\title{
A study on the deposition efficiency, porosity and redox behavior of Prussian blue thin films using an EQCM ${ }^{\text {is }}$
}

\author{
Cheng-Lan Lin, Kuo-Chuan Ho * \\ Department of Chemical Engineering, National Taiwan University, Taipei 10617, Taiwan, ROC
}

Received 30 August 2001; received in revised form 21 December 2001; accepted 21 December 2001

\begin{abstract}
The deposition efficiency, porosity and redox behavior of Prussian blue (PB) thin films are investigated. To find better deposition conditions, the PB thin films were deposited on a Pt electrode using a potentiostatic method proposed by Mortimer and Rosseinsky (J. Electroanal. Chem. 151 (1983) 133). The optimal deposition potential was determined to be 0.50 V (vs. $\mathrm{Ag} \mid \mathrm{AgCl}$ ) by considering the deposition efficiency and the time needed for the deposition. The mass change on the Pt electrode was monitored using an electrochemical quartz crystal microbalance (EQCM) during the PB deposition. The deposition efficiency was calculated to be about $38 \%$ based on the charge consumption of the PB thin film during the reduction at optimal deposition conditions. The porosity of the PB thin film was estimated to be 0.39 for a PB film with a thickness of $1860 \AA$. During the redox reactions, cations in the electrolytic solutions must be inserted into or extracted out of the PB thin film. The lattice structure of the PB thin film limits its ease of cation insertion. It was found that $\mathrm{K}^{+}$can move in and out of the PB lattices much more easily than $\mathrm{Li}^{+}$because the hydrated radii of the $\mathrm{K}^{+}$ions are smaller than those of the $\mathrm{Li}^{+}$ions. Nevertheless, reduction of the PB thin film can be carried out partially and irreversibly in solutions containing $\mathrm{Li}^{+}$or $\mathrm{H}_{3} \mathrm{O}^{+}$alone. However, a mass loss for the thin film was observed. (c) 2002 Elsevier Science B.V. All rights reserved.
\end{abstract}

Keywords: Deposition efficiency; Electrochemical quartz crystal microbalance (EQCM); Porosity; Prussian blue (PB)

\section{Introduction}

Prussian blue (PB) is a well-known compound in the dying industry. Ellis et al. [1], Itaya et al. [2], and Mortimer and Rosseinsky [3] were among the first few groups to study PB as a modified electrode. After their work, many studies on the electrochemical properties and applications of PB and its analogs in different fields were published. The quartz crystal microbalance (QCM) has been used to study the electrodeposition and the redox behavior of these materials [4-6]. In addition to its use in electrochromic devices [7], PB applications were also proposed in many areas, such as solid-state thin film batteries $[8,9]$, electrocatalytic reac-

\footnotetext{
4 Paper No. P43 presented at the 9th International Conference on Electrified Interfaces, Wolfville, Nova Scotia, Canada, July 8-13, 2001.

* Corresponding author. Tel.: + 886-2-2366-0739; fax: + 886-22362-3040.

E-mail address: kcho@ms.cc.ntu.edu.tw (K.-C. Ho).
}

tions [10,11], detectors [12], ion-selective electrodes $[13,14]$, and photochargable devices [15].

PB is a "mixed valent compound" or "transition metal hexacyanide," that can be formulated as $\mathrm{M}_{k}^{\mathrm{A}}\left[\mathrm{M}^{\mathrm{B}}(\mathrm{CN})_{6}\right]_{l}$, where $\mathrm{M}^{\mathrm{A}}$ and $\mathrm{M}^{\mathrm{B}}$ are transition metals, $k$ and $l$ are integer constants. Keggin and Miles [16] first studied the PB cell structure. PB has a facecentered structure with a unit cell constant equal to $10.2 \AA[16]$. With the aid of X-ray powder diffraction, they discovered that there were two different structures for PB, called insoluble $\mathrm{PB}\left(\mathrm{Fe}_{4}\left[\mathrm{Fe}(\mathrm{CN})_{6}\right]_{3}\right)$ and soluble $\mathrm{PB}\left(\mathrm{KFeFe}(\mathrm{CN})_{6}\right)$. The difference between insoluble and soluble $\mathrm{PB}$ results from the degree of peptization to potassium salts. Both are nearly insoluble in water. It is easy for soluble PB to undergo peptization with potassium salts in solutions, so they are called "soluble" by dying industrialists. These compounds have a 3D structure similar to the crosslinking in polymers, thus they can be easily combined with solvents and their stoichiometric number may change. For insoluble PB, ferric ions occupy the cell interstitial sites. In soluble $\mathrm{PB}$, the 
structure is basically the same except that potassium ions replace some of the ferric ions in the interstitial sites. PB acts like a zeolite and the diameter of the channel formed by the lattices is about $3.2 \AA$. The size of the cations inserting/extracting into and/or out of the PB lattice structure during the redox reaction is therefore limited [2]. Ferric ions in the PB lattice are reduced to ferrous ions and transform PB into a colorless compound at $0.2 \mathrm{~V}$ (vs. SCE) called "Everitt's salt (ES)." ES has almost the same lattice structure as PB. The cell constant of ES is also $10.2 \AA$.

In this study, the effect of applied potential on the deposition efficiency of PB thin film was studied. Both the deposition efficiency based on the charge consumption and the deposition efficiency based on the mass gain are defined. By measuring the redox charge consumption of the PB thin film or the mass gain after the deposition with an EQCM, both deposition efficiencies can be calculated. The porosity and the apparent density are also estimated. Moreover, the redox behavior of the PB thin film in solutions containing different cations are studied in this research.

\section{Experimental}

All chemicals used were reagent grade without further purification. Deionized water was used throughout. The conventional three-electrode system was employed in all electrochemical experiments. A Pt electrode with an area of $0.196 \mathrm{~cm}^{2}(0.5 \mathrm{~cm}$ diameter $)$ on the quartz crystal plate was used as the working electrode. A Pt foil was used as the counter electrode. A homemade $\mathrm{Ag}|\mathrm{AgCl}| \mathrm{KCl}_{\text {sat }}$ electrode was used as the reference

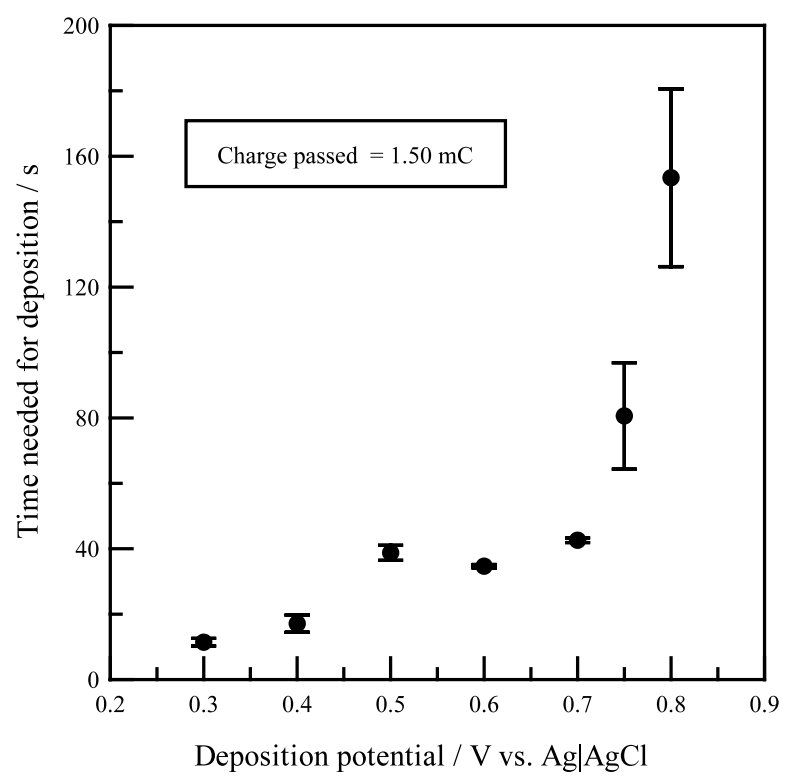

Fig. 1. The time needed for the deposition of PB thin films under various deposition potentials. electrode. All potentials were recorded and are reported with respect to this reference electrode.

The PB thin films were prepared using a potentiostatic method proposed by Mortimer and Rosseinsky [3] from an equivolume mixture of $20 \mathrm{mM} \mathrm{K}_{3} \mathrm{Fe}(\mathrm{CN})_{6}$ and $20 \mathrm{mM} \mathrm{FeCl}$ aqueous solutions under various applied potentials. The solution was not stirred. The in situ mass changes of the Pt electrodes were monitored using a quartz crystal analyzer (QCA) during the deposition process. The mass changes were calculated from the frequency changes through the Sauerbrey equation [17]. The applied potentials were cut off to end the deposition once $1.50 \mathrm{mC}$ of charge passed to the electrode. The time needed for the deposition and the mass gain of the $\mathrm{Pt}$ electrode during the deposition were recorded. After the deposition, the PB thin film electrode was washed thoroughly with deionized water twice and stored in air for several days before proceeding with further experiments.

The voltammetric measurements and potential-step experiments were carried out with the usual three-electrode configuration in combination with a Seiko EG\&G QCA (model QCA917). The QCA employed AT-cut quartz wafers with fundamental frequencies near 9.0 MHz. An Eco Chemie (model PGSTAT30) instrument was employed to control the potentials applied to the electrode.

\section{Results and discussion}

\subsection{Deposition of the $P B$ thin films}

There are two major electrodeposition methods for the preparation of PB film, namely, the galvanostatic method [3] and the potentiostatic method $[3,18]$. In the galvanostatic method, the potential of the electrode is changed with time (the potential is changed from about $1.0 \mathrm{~V}$ to various other values depending on the current density employed), which means the driving force during the deposition is not a constant, and the PB deposited gavanostatically might possess different forms or structures as compared to that of PB deposited potentiostatically. In this study, the potentiostatic method was chosen to prepare the PB film, with the aim of finding an optimal deposition potential.

The cathodic electrodeposition of the PB thin film deposition can be expressed as follows:

$4 \mathrm{Fe}^{3+}+3 \mathrm{Fe}(\mathrm{CN})_{6}^{3-}+3 \mathrm{e}^{-} \rightarrow \mathrm{Fe}_{4}\left[\mathrm{Fe}(\mathrm{CN})_{6}\right]_{3}$

Due to the reductive nature of the deposition reaction, a more positive applied potential corresponds to a smaller driving force and a longer time should be needed for the deposition. The time needed for the deposition increases with the applied potential, as is shown in Fig. 1. The reproducibility of the experimen- 
tal data was verified three times for an applied potential $\leq 0.7 \mathrm{~V}$, and five times for an applied potential $>0.7$ $\mathrm{V}$, as indicated by the error bars in Fig. 1. Fig. 1 shows that the larger the applied deposition potential, the smaller is the driving force and thus the longer the average time needed for the deposition. Fig. 1 also shows that the smaller the driving force for the deposition, the larger is the variance (or the error bar) in the time needed for the deposition. The mass gains of the Pt electrode during deposition under different applied potentials are shown in Fig. 2. Once again, the mass gain data were repeated three to five times at each potential level. The largest average mass gain was obtained with the applied potential at $0.5 \mathrm{~V}$ (vs. $\mathrm{Ag} \mid \mathrm{AgCl})$.

Although the same potential was applied during the deposition of PB thin films, the time needed for the deposition and the mass gain after the deposition can be still different, i.e. variation from run to run. In general, these are affected by at least three factors: surface conditions of the electrode, composition and aging of the plating solution and the applied potential during the deposition process. Smaller applied potentials during the deposition correspond to a faster growth rate of $\mathrm{PB}$, cause greater roughness of the $\mathrm{PB}$ film surface at the initial stage of the film deposition, and then affect the subsequent growth of the PB film [18]. This also makes the surface roughness conditions of the electrode a relatively minor factor and thus the variance in the time needed for deposition is small. On the other hand, when the applied driving force is small (more positive potential), the surface conditions become a dominating factor and the variance in the time needed increases. Composition of the plating solution, such as

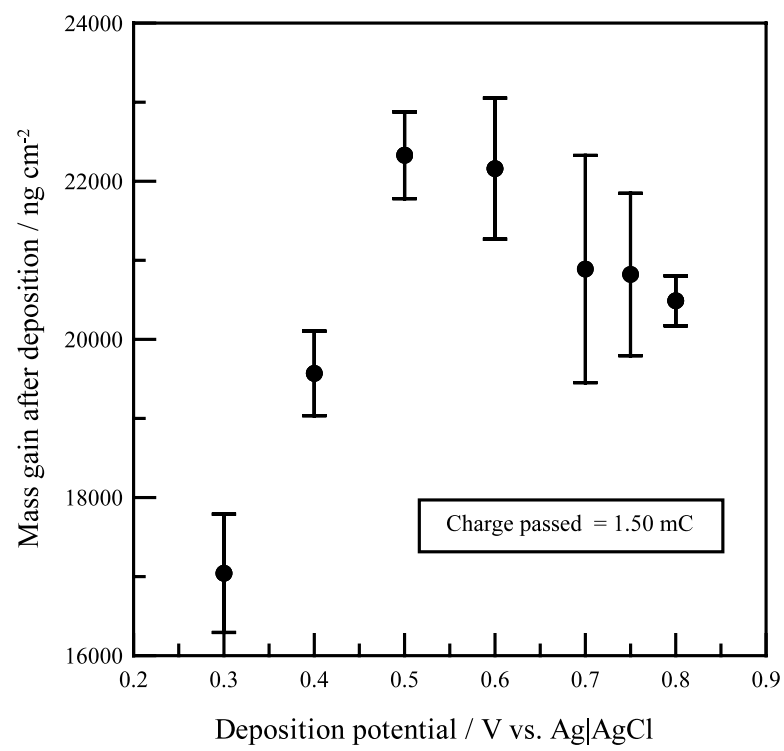

Fig. 2. The mass gains on the Pt electrode after PB thin film deposition under various deposition potentials. the concentrations of the $\mathrm{Fe}^{3+}$ or $\mathrm{Fe}(\mathrm{CN})_{6}^{3-}$ and the ratio of their amounts, will affect the quality of the $\mathrm{PB}$ film deposited $[3,18]$. The plating solution will form a colloid, which is a complex of $\left[\mathrm{Fe}^{3+} \mathrm{Fe}(\mathrm{CN})_{6}^{3-}\right]$ in the solution, causing a change of concentration in the plating solution, and thus may affect the deposition of the PB film.

At each applied potential, the variance in the mass gain is different. A small variance can be achieved by controlling the electrode potential at $0.8 \mathrm{~V}$, as is shown in Fig. 2. However, this will prolong the time needed for deposition.

Since $\mathrm{Fe}^{3+}, \mathrm{Cl}^{-}, \mathrm{K}^{+}$, and $\left[\mathrm{Fe}(\mathrm{CN})_{6}\right]^{3-}$ coexist in the plating solution, the following reactions might also take place during $\mathrm{PB}$ thin film deposition:

$$
\begin{aligned}
& \mathrm{Fe}^{3+}+\mathrm{e}^{-} \rightarrow \mathrm{Fe}^{2+}\left(E^{\circ}=0.771 \mathrm{~V} \text { vs. SHE }\right) \\
& {\left[\mathrm{Fe}(\mathrm{CN})_{6}\right]^{3-}+\mathrm{e}^{-}} \\
& \rightarrow\left[\mathrm{Fe}(\mathrm{CN})_{6}\right]^{4-}\left(E^{\circ}=0.361 \mathrm{~V} \text { vs. SHE }\right)
\end{aligned}
$$

Reaction (3) is not likely to occur if the applied potential is more positive than $0.361 \mathrm{~V}$ versus SHE, or 0.139 $\mathrm{V}$ versus $\mathrm{Ag} \mid \mathrm{AgCl}$, but reaction (2) can be activated if the applied potential during deposition is more negative than $0.771 \mathrm{~V}$ versus SHE, or $0.549 \mathrm{~V}$ versus $\mathrm{Ag} \mid \mathrm{AgCl}$, which corresponds to a larger driving force for reaction (2), thus more $\mathrm{Fe}^{2+}$ will be generated on the electrode surface. It can be seen from Fig. 2 that this occurs when the applied potential is more negative than $0.5 \mathrm{~V}$ (vs. $\mathrm{Ag} \mid \mathrm{AgCl}$ ) and causes the $\mathrm{PB}$ to be generated in a voluminous non-adherent state [19]. Therefore, the average mass gain measured after the deposition decreases when the applied potential is more negative than $0.5 \mathrm{~V}$ (vs. $\mathrm{Ag} \mid \mathrm{AgCl}$ ) during the deposition.

\subsection{Deposition efficiency}

The PB thin film deposition efficiency can be defined in two different ways: (1) deposition efficiency based on the charge consumption, $\eta_{\mathrm{q}}$, and (2) deposition efficiency based on the mass gain, $\eta_{\mathrm{m}}$, which can be defined as follows:

$\eta_{\mathrm{q}}=$

(charge consumed during the reduction of PB to ES ) (charge consumed during the deposition) $\times 100 \%$

$\eta_{\mathrm{m}}$

$$
\begin{aligned}
& =\frac{\text { (actual mass gain measured during the deposition) }}{\text { (theoretical mass gain during the deposition) }} \\
& \quad \times 100 \%
\end{aligned}
$$


$\eta_{\mathrm{q}}$ is a measure of the percentage of total charge passed to the electrode to form the $\mathrm{Fe}^{3+}$ sites in the PB lattices during $\mathrm{PB}$ deposition as judged by the $\mathrm{PB}$ reduction to form ES potentiostatically. $\eta_{\mathrm{m}}$ is a measure of the difference between the expected and the actual mass gain during PB deposition. For the estimation of $\eta_{\mathrm{q}}$, the charge consumed during the reduction of $\mathrm{PB}$ to ES can be estimated by performing cyclic voltammetry (CV) or potential-step (PS) experiments in $1 \mathrm{M} \mathrm{KCl}$ and $0.01 \mathrm{M}$ $\mathrm{HCl}$ solution with in situ mass changes monitored using an EQCM. As mentioned earlier, PB has two different forms, insoluble $\mathrm{PB}\left(\mathrm{Fe}_{4}\left[\mathrm{Fe}(\mathrm{CN})_{6}\right]_{3}\right)$ and soluble $\mathrm{PB}$ $\left(\mathrm{KFeFe}(\mathrm{CN})_{6}\right)$. PB modified electrodes made by electrochemical methods yield insoluble PB. Potential cycling transforms an insoluble PB film into a mixture of insoluble and soluble PB [20]. It is well accepted that cation insertion into the PB lattice structure is accomplished by the reduction of $\mathrm{PB}$, which causes mass change in the $\mathrm{PB}$ thin films. The insertion reactions, for both insoluble and soluble $\mathrm{PB}$, can be expressed by Eqs. (6) and (7), respectively [21]:

$$
\mathrm{Fe}_{4}^{\mathrm{III}}\left[\mathrm{Fe}^{\mathrm{II}}(\mathrm{CN})_{6}\right]_{3}+4 \mathrm{M}^{+}+4 \mathrm{e}^{-} \rightarrow \mathrm{M}_{4} \mathrm{Fe}_{4}^{\mathrm{II}}\left[\mathrm{Fe}^{\mathrm{II}}(\mathrm{CN})_{6}\right]_{3}
$$

$\mathrm{KFe}^{\mathrm{III}}\left[\mathrm{Fe}^{\mathrm{II}}(\mathrm{CN})_{6}\right]+\mathrm{M}^{+}+\mathrm{e}^{-} \rightarrow \mathrm{MKFe}^{\mathrm{II}}\left[\mathrm{Fe}^{\mathrm{II}}(\mathrm{CN})_{6}\right]$

where $\mathrm{M}^{+}$is the cation in the electrolyte solution, such as $\mathrm{K}^{+}, \mathrm{Li}^{+}$or $\mathrm{H}^{+}$etc. All $\mathrm{Fe}^{3+}$ sites in the PB lattices can be reduced in the potential scan range between 0.7 and $-0.2 \mathrm{~V}$ (vs. $\mathrm{Ag} \mid \mathrm{AgCl}$ ). Even though the PB film transforms into a mixture of insoluble and soluble PB during potential cycling, Eqs. (6) and (7) show that the stoichiometry, or the number of cations per electron, is the same for both PB forms. This implies that the proposed method for evaluating $\eta_{\mathrm{q}}$ in Eq. (4) is suitable for both forms of PB.

Fig. 3 shows $\mathrm{CVs}$ of the $\mathrm{PB}$ thin film in $1 \mathrm{M} \mathrm{KCl}$ solution for the first and third cycles and the corresponding mass changes. The reduction peak at around $0.40 \mathrm{~V}$ (vs. $\mathrm{Ag} \mid \mathrm{AgCl}$ ) for the first cycle corresponds to the reduction of $\left[\mathrm{Fe}(\mathrm{CN})_{6}\right]^{3-}$ to $\left[\mathrm{Fe}(\mathrm{CN})_{6}\right]^{4-}$, and disappears at the third cycle. From the corresponding mass changes in Fig. 3(b), there is an irreversible mass loss $\left(\sim 400 \mathrm{ng} \mathrm{cm}^{-2}\right)$ of the PB thin film during the first cycle. The above two phenomena imply that there are some foreign ions, other than the PB molecules, that are co-deposited onto the $\mathrm{Pt}$ electrode, which accounts for the extra charge consumption during the $\mathrm{CV}$ experiments. In fact, foreign ions such as $\mathrm{Fe}^{3+}$ or $\left[\mathrm{Fe}(\mathrm{CN})_{6}\right]^{3-}$ present in the plating solution might be trapped in the PB thin film during the deposition and the extra charge might be consumed by the reduction reactions, according to Eqs. (2) and (3), during the CV experiments. These foreign ions show up in the plating solution only during deposition, not in the solution
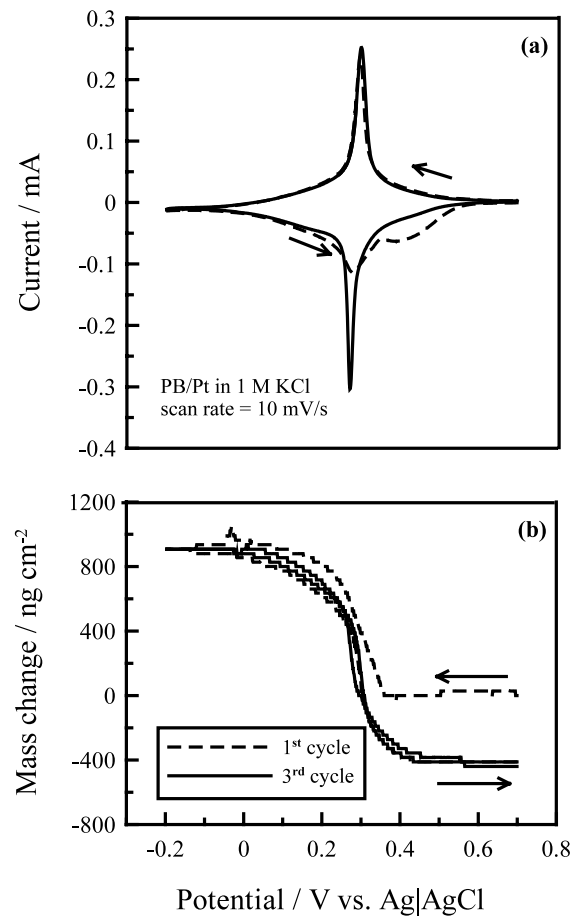

Fig. 3. (a) Cyclic voltammograms of the $\mathrm{PB}$ thin film in $1 \mathrm{M} \mathrm{KCl}$ solution (scan rate $=10 \mathrm{mV} \mathrm{s}^{-1}$ ) for the first and third cycle, and (b) the corresponding mass changes.

used for $\mathrm{CV}$ experiments, as the latter contains only 1 $\mathrm{M} \mathrm{KCl}$ solution. Fig. 4 shows the transient current of the $\mathrm{PB}$ thin film switched using a double potential step $(-0.20$ and $+0.70 \mathrm{~V})$ in $1 \mathrm{M} \mathrm{KCl}$ solution and the corresponding mass changes. The degree of $\mathrm{PB}$ reduction is proportional to the absorbance change of the thin film [22]. The mass changes during the reduction, recorded either by the CV or the PS experiments, are almost the same; but the charge consumed using the $\mathrm{CV}$ is generally about three to four times larger than that recorded using the PS method. Under the same operating potential domain (between 0.7 and $-0.2 \mathrm{~V}$ vs. $\mathrm{Ag} \mid \mathrm{AgCl}$ ), the degree of reduction caused by the $\mathrm{CV}$ and the PS experiments should be the same. In fact, similar mass changes have been observed during the reduction, as shown in Fig. 3(b) and Fig. 4(b). This implies that some side reactions take place during the CV scan and cause extra charge consumption during the reduction. Thus, the charge consumed during the $\mathrm{PB}$ reduction measured by the PS experiments is used to calculate $\eta_{\mathrm{q}}$. The charge consumed, for both the CV and PS experiments after the reduction of PB to ES, is shown in Fig. 5. With a known amount of charge injection at the level of $1.5 \mathrm{mC}$, the values of $\eta_{\mathrm{q}}$ under different applied potentials can be calculated and the results are shown in Fig. 7. These values are around $20-40 \%$ with an average value of $33.6 \%$. 

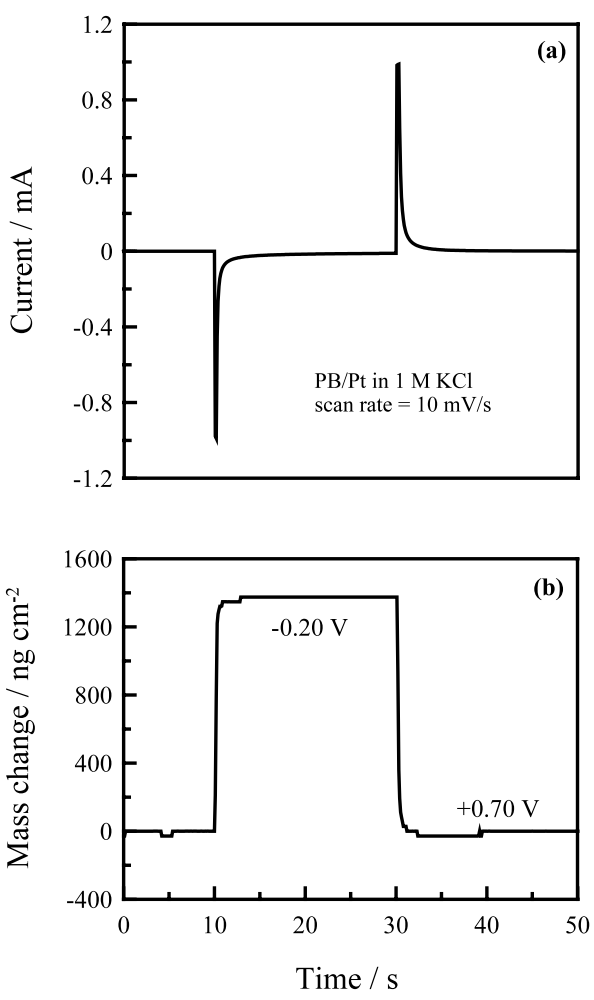

Fig. 4. (a) The current transient of PB thin film switched using a double potential step $(-0.20$ and $+0.70 \mathrm{~V})$ in $1 \mathrm{M} \mathrm{KCl}$ solution, and (b) the corresponding mass changes.

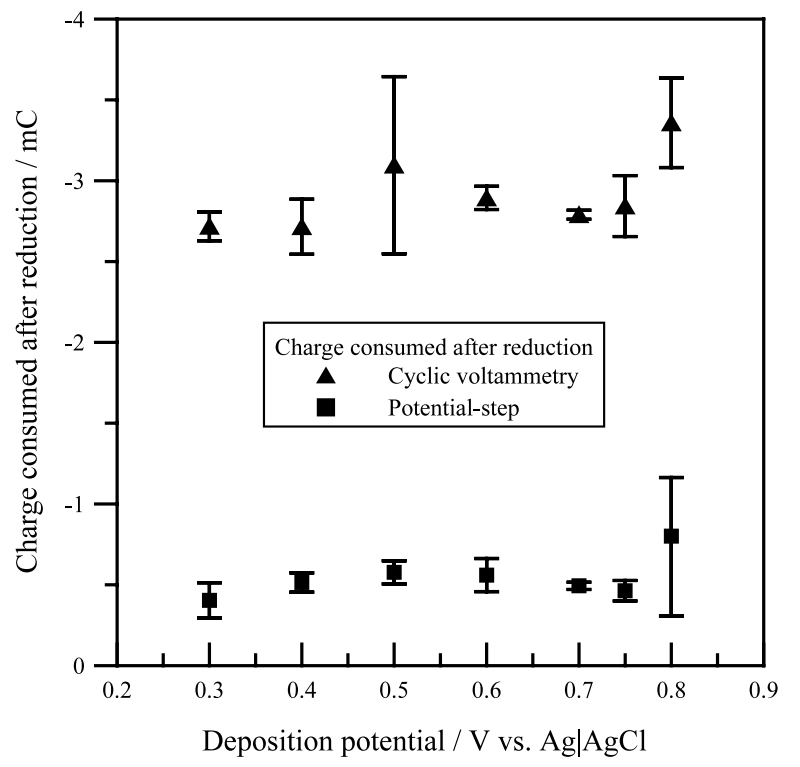

Fig. 5. The PB thin film charge consumed after reduction, as measured by the reduction of PB to ES using the CV and the PS methods.

In the estimation of $\eta_{\mathrm{m}}$, the actual mass gain on the Pt electrode during the depositions can be measured using an in situ EQCM. The maximum mass gain is attained under the assumption that all charge passed
$(1.5 \mathrm{mC})$ forms $\mathrm{PB}$ thin film without any loss or side reactions. In addition, $\mathrm{PB}$ with the formula $\mathrm{Fe}_{4}\left[\mathrm{Fe}(\mathrm{CN})_{6}\right]_{3} \cdot 14 \mathrm{H}_{2} \mathrm{O}[23]$ is assumed in the calculation. The actual mass changes in the $\mathrm{PB}$ thin films during the reduction of $\mathrm{PB}$ to $\mathrm{ES}$, at various deposition potentials, are shown in Fig. 6. The deposition efficiencies based on the mass change, $\eta_{\mathrm{m}}$, are around $60-80 \%$ over a wide potential range, with an average value of $69.5 \%$, as is shown in Fig. 7. The deposition efficiency based

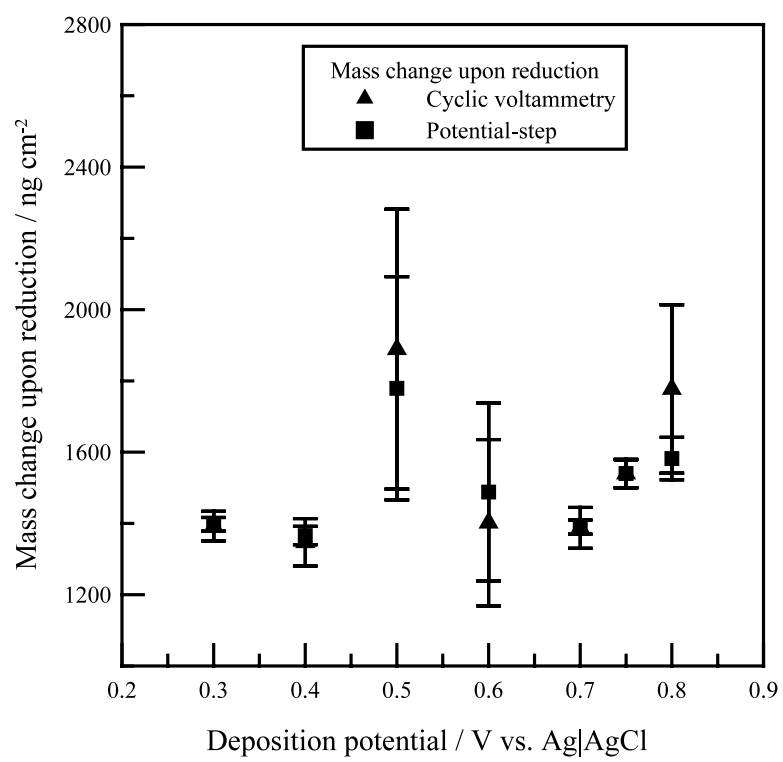

Fig. 6. The mass change in the PB thin film upon reduction to form ES using the CV and the PS methods.

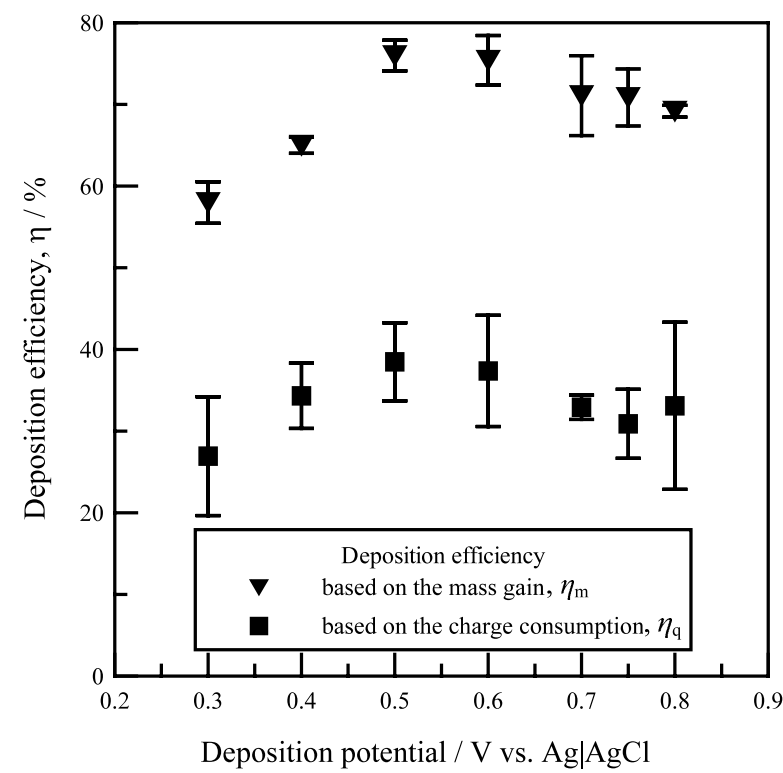

Fig. 7. The plot of the deposition efficiency based on the charge consumption $\left(\eta_{\mathrm{q}}\right)$ and the deposition efficiency based on the mass gain $\left(\eta_{\mathrm{m}}\right)$ vs. the deposition potentials. 
on the mass gain, $\eta_{\mathrm{m}}$, is overestimated owing to the coexistence of foreign ions in the PB thin film.

\subsection{Porosity and apparent density of the PB film}

The porosity of the PB thin film, $\varepsilon$, can be estimated as follows:

$\varepsilon=1-\frac{\text { (theoretical film thickness calculated) }}{\text { (actual film thickness measured ) }}$

The practical meaning of porosity for a thin film implies the percentage of the thin film volume which is porous, or filled with open spaces. Assuming that there is no defect in the PB lattice structure and that a $100 \%$ Faradaic efficiency occurs for the reduction of PB to ES without involving any side reactions, the theoretical film thickness of the PB can be calculated to be $1140 \AA$. Because the average film thickness measured was 1860 $\AA$ for a PB thin film with a $5 \mathrm{mC} \mathrm{cm}^{-2}$ charge capacity, the apparent density of the $\mathrm{PB}$ thin film was estimated to be 1.52 , which is in reasonable agreement with the value of 1.78 reported by Ludi and Gudel [24] and 1.40 reported by Itaya et al. [25]. The porosity of the PB thin film estimated by Eq. (8) was 0.39.

\subsection{The influence of cations on the PB redox behavior}

The ground state of the PB thin film is blue. PB can be reduced under suitable conditions to form colorless ES according to Eq. (6) or Eq. (7). Many researchers have observed for PB type modified electrodes that cations with smaller Stokes' radii penetrate more easily [3,26-30]. Penetration was demonstrated by changing the supporting electrolytes and observing the remarkable voltammetric behavior of PB. For example, Kulesza et al. [31] have studied the spectroelectrochemical behavior of PB in various electrolytes. In our study, the cation effect on the PB redox behavior is emphasized. To avoid excessive description of Group IA cations, we have limited our focus on $\mathrm{Li}^{+}$and $\mathrm{K}^{+}$, as both are representative Group IA cations for PB and its analogs. Fig. 8(a), (b), and (c) show the typical CV and corresponding mass change in $\mathrm{PB}$ modified electrodes obtained with $1 \mathrm{M} \mathrm{KCl}+0.01 \mathrm{M} \mathrm{HCl}, 1 \mathrm{M} \mathrm{LiCl}+0.01$ $\mathrm{M} \mathrm{HCl}$, and $0.01 \mathrm{M} \mathrm{HCl}$, respectively. All electrolytes were adjusted with $\mathrm{HCl}$ to obtain a constant $\mathrm{pH}$ value (pH 2.0). A well-defined redox pair appears in Fig. 8(a) but not in Fig. 8(b) and 8(c), which implies that the hydrated $\mathrm{K}^{+}$ions can enter the PB lattices more easily than $\mathrm{Li}^{+}$and $\mathrm{H}^{+}$ions during the reduction process [31]. The PB lattice structure acts as a molecular sieve and the radius of the hydrated cations being inserted is limited to $1.6 \AA$. The radii of the hydrated ions calculated from the limiting mobility using the Stokes' law for $\mathrm{K}^{+}$and $\mathrm{Li}^{+}$are 1.25 and $2.37 \AA$ [2], respectively.
Theoretically, the hydrated $\mathrm{K}^{+}$ions can enter the $\mathrm{PB}$ lattices more easily than the hydrated $\mathrm{Li}^{+}$ions. The results shown in Fig. 8(a) and (b) are consistent with the theoretical prediction.

Although the hydrated $\mathrm{Li}^{+}$ions are inserted with difficulty into the PB lattices during the potential scan, mass changes are still observed in Fig. 8(b). However, the blue color of the thin film becomes lighter after the $\mathrm{CV}$ experiment, as judged by the naked eye. The $\mathrm{CV}$ and the corresponding mass change in the $\mathrm{PB}$ thin film in a solution containing only $0.01 \mathrm{M} \mathrm{HCl}$ is also shown in Fig. 8(c). No well-defined peaks exist, but the mass changes and color lightening in the thin film can still be observed during the potential scan, which suggests that $\mathrm{H}_{3} \mathrm{O}^{+}$does cause irreversible reduction in the $\mathrm{PB}$ thin film. It may be true that some $\mathrm{K}^{+}$can be trapped in the defect structure of $\mathrm{PB}$, but the amount of trapped $\mathrm{K}^{+}$ simply is not enough to cause a major color change observed during the reduction for a practical film thickness, regardless of the structure and the composition of a PB thin film. Moreover, color changes observed during the redox processes in the presence of $0.01 \mathrm{M}$ $\mathrm{HCl}$ were nearly irreversible, suggesting the difficult extraction of $\mathrm{H}_{3} \mathrm{O}^{+}$in an aqueous solution containing protons. Determination of the detailed mechanism for proton insertion requires further investigation on the interaction between the inserted ions and the PB film.

\section{Conclusions}

The deposition of PB thin film onto a Pt electrode using a potentiostatic method was investigated over a wide potential range. In a plating solution containing equal volume mixtures of $20 \mathrm{mM} \mathrm{FeCl}{ }_{3}$ and $20 \mathrm{mM}$ $\mathrm{K}_{3} \mathrm{Fe}(\mathrm{CN})_{6}$, an applied potential of $0.5 \mathrm{~V}$ (vs. $\mathrm{Ag} \mid \mathrm{AgCl}$ ) is suggested from the viewpoint of the deposition efficiency and the time needed for deposition. The ease of reduction of $\mathrm{PB}$ to $\mathrm{ES}$ is most important in practical applications for PB thin film. Thus, a deposition efficiency based on the charge consumption, $\eta_{\mathrm{q}}$, is preferred. Because the charge injected into the electrode during deposition is utilized by some side reactions, $\eta_{\mathrm{q}}$ is usually less than $40 \%$. In principle, the deposition efficiency can be improved by adjusting the composition of the plating solution. This study also suggests a method by which to judge the porosity and the apparent density of a PB thin film. Hydrated cations in the electrolyte solution can generally be inserted into the PB lattices during PB reduction, but the ease of cation insertion, into and out of PB film, is limited by the ionic radius. Of the various cations studied, $\mathrm{K}^{+}$is the best. Although the insertion of other cations can reduce PB, the reaction apparently becomes irreversible, as the 

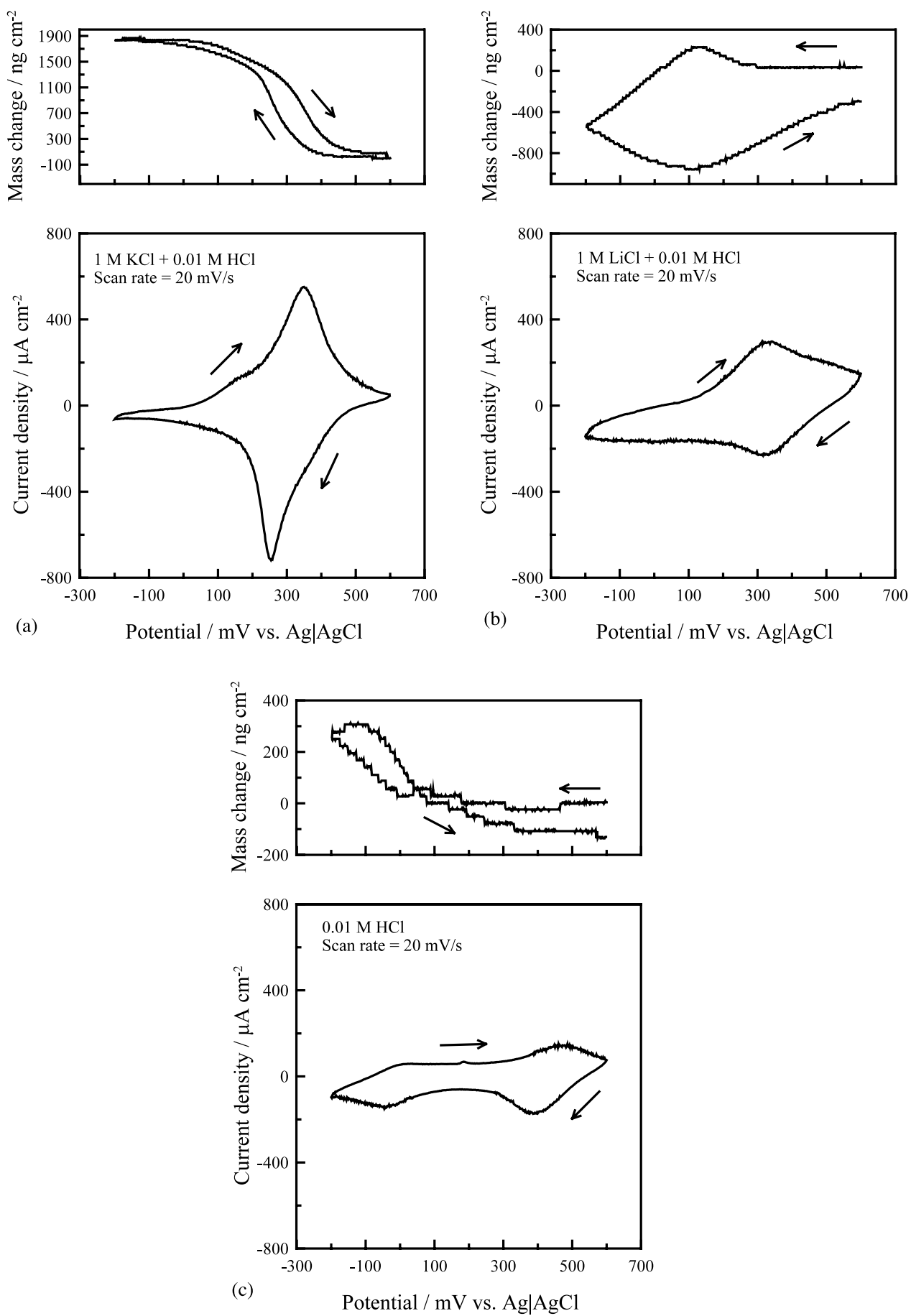

Fig. 8. Cyclic voltammograms and the corresponding mass changes recorded in solutions containing (a) $1 \mathrm{M} \mathrm{KCl}$ and $0.01 \mathrm{M} \mathrm{HCl}$, (b) $1 \mathrm{M} \mathrm{LiCl}$ and $0.01 \mathrm{M} \mathrm{HCl}$, and (c) $0.01 \mathrm{M} \mathrm{HCl}$. Scan rate $=20 \mathrm{mV} \mathrm{s}^{-1}$.

reduced $\mathrm{PB}$ thin film is unable to re-oxidize to its ground state.

\section{Acknowledgements}

This work is being supported by the National Science
Council of the Republic of China under grant no. NSC 89-2214-E002-072.

\section{References}

[1] D. Ellis, M. Eckhoff, V.D. Neff, J. Phys. Chem. 85 (1981) 1225. 
[2] K. Itaya, T. Ataka, S. Toshima, J. Am. Chem. Soc. 104 (1982) 4767.

[3] R.J. Mortimer, D.R. Rosseinsky, J. Electroanal. Chem. 151 (1983) 133.

[4] B.J. Feldman, O.R. Melroy, J. Electroanal. Chem. 234 (1987) 213.

[5] E. Czirók, J. Bácskai, P.J. Kulesza, G. Inzelt, A. Wolkiewicz, K. Miecznikowski, M.A. Malik, J. Electroanal. Chem. 405 (1996) 205.

[6] M.A. Malik, K. Miecznikowski, P.J. Kulesza, Electrochim. Acta 45 (2000) 3777.

[7] P.M.S. Monk, R.J. Mortimer, D.R. Rosseinsky, Electrochromism: Fundamentals and Applications, VCH, Weinheim, Germany, 1995 Ch. 6.

[8] V.D. Neff, J. Electrochem. Soc. 132 (1985) 1382.

[9] M. Kaneko, T. Okada, J. Electroanal. Chem. 255 (1988) 45.

[10] K. Itaya, N. Shoji, I. Uchida, J. Am. Chem. Soc. 106 (1984) 3423.

[11] K. Ogura, I. Yoshida, Electrochim. Acta 32 (1987) 1191.

[12] M.R. Deakin, H. Byrd, Anal. Chem. 61 (1989) 290.

[13] T. Ikeshoji, J. Electrochem. Soc. 133 (1986) 2108.

[14] Z. Gao, X. Zhou, G. Wang, R. Li, Z. Zhao, Anal. Chim. Acta 244 (1991) 39.
[15] M. Kaneko, K. Takahashi, E. Tsuchida, J. Electroanal. Chem. 227 (1987) 255.

[16] J.F. Keggin, F.D. Miles, Nature 137 (1936) 577.

[17] G.Z. Sauerbrey, Z. Phys. 155 (1959) 206.

[18] R.J. Mortimer, D.R. Rosseinsky, A. Glidle, Sol. Energy Mater. Solar Cells 25 (1992) 211.

[19] C. Kuhnhardt, J. Electroanal. Chem. 369 (1994) 71.

[20] C.A. Lundgren, R.W. Murray, Inorg. Chem. 27 (1988) 933.

[21] K. Itaya, I. Uchida, V.D. Neff, Acc. Chem. Res. 19 (1986) 162.

[22] J.W. McCargar, V.D. Neff, J. Phys. Chem. 92 (1988) 3598.

[23] F. Herren, P. Fischer, A. Ludi, W. Halg, Inorg. Chem. 19 (1980) 956.

[24] A. Ludi, H.U. Gudel, Struct. Bonding (Berlin) 14 (1973) 1.

[25] K. Itaya, H. Akahoshi, S. Toshima, J. Electrochem. Soc. 129 (1982) 1498.

[26] Z. Jin, S. Dong, Electrochim. Acta 35 (1990) 1057.

[27] R.J. Mortimer, D.R. Rosseinsky, J. Electroanal. Chem. 151 (1993) 133.

[28] K. Itaya, I. Uchida, V.D. Neff, Acc. Chem. Res. 19 (1986) 162.

[29] F. Li, S. Dong, Sci. Sin. Ser. B 30 (1987) 367.

[30] S. Dong, Z. Jin, Electrochim. Acta 34 (1989) 963.

[31] P.J. Kulesza, S. Zamponi, M.A. Malik, K. Miecznikowski, M. Berrettoni, R. Marassi, J. Solid State Electrochem. 1 (1997) 88. 